\title{
Diabetes mellitus increases the risk of intrahepatic recurrence of hepatocellular carcinoma after surgical resection
}

\author{
Yunseon $\mathrm{Choi}^{1}$, YoungKil Choi ${ }^{2}$, Chang Soo $\mathrm{Choi}^{2}$, Yun-Han Lee ${ }^{3}$ \\ ${ }^{1}$ Department of Radiation Oncology, Inje University School of Medicine, Busan Paik Hospital, Busan - Korea \\ ${ }^{2}$ Department of General Surgery, Inje University School of Medicine, Busan Paik Hospital, Busan - Korea \\ ${ }^{3}$ Department of Molecular Medicine, College of Medicine, Keimyung University, Daegu - Korea
}

\begin{abstract}
Aims and background: The relationship between cancer and metabolism has recently been receiving attention. We investigated the prognostic influence of type 2 diabetes mellitus in patients with hepatocellular carcinoma (HCC) treated with curative resection.

Methods and study design: The records of 58 patients who underwent curative resection for HCC PT1-2NOMO between 2010 and 2014 were reviewed retrospectively. Fourteen patients (24.1\%) had diabetes mellitus at diagnosis. Local control (LC) was defined as time to recurrence in the liver.

Results: The median follow-up was 23.3 months. Relapses occurred in 20 patients (34.5\%) during the follow-up period; 17 of them developed intrahepatic recurrence, which was associated with diabetes mellitus $(p=0.013)$ and alpha fetoprotein (AFP) levels $>500 \mathrm{ng} / \mathrm{mL}(p=0.019)$. Overall relapses $(n=20)$ were related to T stage $(p=0.044)$, AFP level $(p=0.005)$, and diabetes $(p=0.044)$. The 3 -year local control (intrahepatic control), diseasefree survival, and overall survival rates were $56.7 \%, 50.5 \%$, and $84.3 \%$, respectively. LC was affected by diabetes mellitus $(p=0.046)$, Barcelona Clinic Liver Cancer staging $(p<0.001)$, Milan criteria for transplantation $(p=0.041)$, serosal invasion $(p=0.032)$, and microvascular invasion $(p=0.043)$. Diabetes was also associated with reduced LC in the subgroup with hepatitis B-related $\mathrm{HCC}(n=44, p=0.028)$.

Conclusions: Diabetes mellitus is correlated with intrahepatic HCC recurrence after surgery. Greater attention should be paid to managing patients with $\mathrm{HCC}$ and diabetes mellitus.
\end{abstract}

Keywords: Diabetes mellitus, Hepatocellular carcinoma, Hepatitis B

\section{Introduction}

The association between metabolism and cancer has been recognized recently, and is considered a new field of study $(1,2)$. Cancer incidence and progression are related to the body's metabolic status $(1,3)$. The metabolic syndrome (including obesity, diabetes mellitus, hyperlipidemia, and hypertension) is known to be closely associated with cancer incidence and mortality $(4,5)$. Keum et al $(6)$ recently reported the results of a meta-analysis on the association between

Accepted: December 4, 2016

Published online: January 7, 2017

Corresponding author:

Yunseon Choi, MD, PhD

Department of Radiation Oncology

Busan Paik Hospital

Inje University School of Medicine

Bokjiro 75, Busanjin-gu

47392 Busan, Republic of Korea

rtyoon@gmail.com weight gain and cancer occurrence. In addition, Tsugane et al (7) reported that liver cancers are associated with insulin resistance. In particular, diabetes mellitus is known to be a risk factor for hepatocellular carcinoma (HCC) (4) and to affect its prognosis $(8,9)$. A recent meta-analysis by Wang et al (9) showed that diabetes is associated with poor disease-free survival (DFS) (hazard ratio $[H R]=1.46,95 \%$ confidence interval $[\mathrm{Cl}]=1.29-1.66)$ and overall survival $(\mathrm{OS})(\mathrm{HR}=1.57,95 \%$ $\mathrm{Cl}=1.21-2.05)$ in HCC patients. Komura et al (10) reported that diabetes is related to an increased risk of relapse and decreased OS in patients with hepatitis virus C-related HCC after curative resection. Even though the study by Komura et al did not show any prognostic effect of diabetes in patients with hepatitis virus B-related HCC, these results seem to be caused by the fact that only a small number of hepatitis virus B-related HCC patients $(n=25)$ were included in the study (10). Therefore, further evaluation of the effect of diabetes on patients with hepatitis virus B-related HCC is warranted.

Additionally, elevated alpha fetoprotein (AFP) level and Child-Pugh class for patients with liver cirrhosis are wellknown clinical prognostic factors for HCC. For surgically treated patients, positive resection margins, tumor size $>5 \mathrm{~cm}$, and 
vascular invasion $(11,12)$ are generally considered poor prognostic factors.

Metformin (biguanide), which is used to manage diabetes, has been shown to have an antineoplastic effect (13). Both the adenosine monophosphate kinase and phosphatidylinositol-3 kinase pathways are believed to be involved in the anticancer effect of metformin $(14,15)$. The use of metformin is able to improve cancer treatment outcomes in HCC patients with diabetes (16) and should be evaluated further.

HCC is the third most lethal cancer worldwide (17). In particular, East Asia is an endemic area for hepatitis B. Except surgery, there are no other effective curative treatment options for HCC (18). For these reasons, HCC is one of the most common malignancies in Korea, and the second most common cause of cancer-related deaths in Korean men (19). Further clinical investigation is required to find more effective treatment strategies for HCC.

The purpose of this study was to determine the association between HCC recurrence and metabolic syndrome, and in particular the effect of diabetes. In addition, we evaluated the clinical and pathological prognostic factors related to treatment outcomes in patients with curatively resected HCC.

\section{Materials and methods}

We evaluated the medical records of 58 patients with HCC who underwent curative resection between January 2010 and September 2014 at the Inje University Busan Paik Hospital. Every patient received surgical resection and had a pathologically confirmed diagnosis of HCC. None of the patients enrolled in this study had extrahepatic metastases (regional lymph nodal or distant metastases) or a prior medical history of local treatment (surgical resection, radiotherapy, or transarterial chemoembolization). The patients who failed follow-up in the first 3 months after surgery were excluded from the evaluation. This study was approved by the Institutional Review Board of Busan Paik Hospital.

The patient characteristics are summarized in Table I. The median age was 57.5 years (range: $35-75$ years). Fortyeight patients (82.8\%) were men. Fifty-one patients (87.9\%) had single tumors at diagnosis, whereas 7 (12.1\%) had multiple tumors. Patients were classified in accordance with the seventh edition of the American Joint Committee on Cancer Staging Manual. The numbers of patients with stage T1 and T2 disease were $44(75.9 \%)$ and $14(24.1 \%)$, respectively. In addition, most patients had Barcelona Clinic Liver Cancer (BCLC) (20) stage A, and only 2 patients had BCLC stage B. The types of surgery performed were the following: 11 (19.0\%) lobectomies, 8 (13.8\%) partial hepatectomies, 20 (34.5\%) segmentectomies (including 4 lateral segmentectomies), and $19(32.8 \%)$ wedge resections. Two surgeons performed all of the resections in this study. There were 11 patients outside the Milan Criteria for liver transplantation (21).

Forty-seven patients $(81.0 \%)$ had a medical history of hepatitis infection. Among them, 44 patients had viral hepatitis $B$ and 4 had viral hepatitis C ( 1 had both B and C viral hepatitis). In addition, 22 patients (39.7\%) had clinically significant liver cirrhosis.

Pathologically, the high-risk factors for progression included in this study were serosal invasion $(n=4)$, vascular
TABLE I - Patient characteristics $(n=58)$

\begin{tabular}{|c|c|c|}
\hline Charateristics & No. & (\%) \\
\hline \multicolumn{3}{|l|}{ Age (years) } \\
\hline Median age (range) & 57.5 & $(35-75)$ \\
\hline \multicolumn{3}{|l|}{ Sex } \\
\hline Male & 48 & $(82.8)$ \\
\hline Female & 10 & $(17.2)$ \\
\hline \multicolumn{3}{|l|}{ T stage } \\
\hline $\mathrm{T} 1$ & 44 & (75.9) \\
\hline $\mathrm{T} 2$ & 14 & $(24.1)$ \\
\hline \multicolumn{3}{|l|}{ Tumor size $(\mathrm{cm})$} \\
\hline$\leq 5$ & 48 & $(82.8)$ \\
\hline$>5$ & 10 & $(17.2)$ \\
\hline \multicolumn{3}{|l|}{ BCLC stage } \\
\hline A & 56 & $(96.6)$ \\
\hline B & 2 & $(3.4)$ \\
\hline \multicolumn{3}{|l|}{ Milan criteria } \\
\hline Inclusion & 47 & (81.0) \\
\hline Exclusion & 11 & (19.0) \\
\hline \multicolumn{3}{|l|}{ Viral hepatitis } \\
\hline Yes & 47 & (81.0) \\
\hline B & 44 & (75.9) \\
\hline C & 4 & $(6.9)$ \\
\hline No & 11 & $(19.0)$ \\
\hline \multicolumn{3}{|l|}{ Liver cirrhosis } \\
\hline Yes & 22 & (39.7) \\
\hline No & 36 & $(62.1)$ \\
\hline \multicolumn{3}{|l|}{ Type of surgery } \\
\hline Lobectomy & 11 & (19.0) \\
\hline Partial hepatectomy & 8 & $(13.8)$ \\
\hline Segmentectomy & 20 & (34.5) \\
\hline Wedge resection & 19 & (32.8) \\
\hline \multicolumn{3}{|l|}{ Pathological risk factors } \\
\hline Yes & 15 & (25.9) \\
\hline Serosal invasion & 4 & $(6.9)$ \\
\hline Microvascular invasion & 8 & $(13.8)$ \\
\hline Resection margin involvement & 6 & $(10.3)$ \\
\hline No & 43 & $(74.1)$ \\
\hline \multicolumn{3}{|l|}{ Histological grade } \\
\hline $\mathrm{G} 1$ & 3 & $(5.2)$ \\
\hline $\mathrm{G} 2$ & 30 & $(51.7)$ \\
\hline G3 & 25 & $(43.1)$ \\
\hline \multicolumn{3}{|l|}{ Alpha fetoprotein (ng/mL) } \\
\hline$\leq 500$ & 51 & (87.9) \\
\hline$>500$ & 7 & $(12.1)$ \\
\hline \multicolumn{3}{|l|}{ Diabetes } \\
\hline Yes & 14 & $(24.1)$ \\
\hline No & 44 & (75.9) \\
\hline \multicolumn{3}{|l|}{ Obesity } \\
\hline Yes & 25 & $(43.1)$ \\
\hline No & 33 & $(56.9)$ \\
\hline
\end{tabular}

$\mathrm{BCLC}=$ Barcelona Clinic Liver Cancer. 
invasion $(n=8)$, and positive resection margins $(n=6)$. According to the pathological reports, 10 patients $(17.2 \%)$ had tumors larger than $5 \mathrm{~cm}$; in cases of multifocal tumors, the diameter of the largest tumor was used as the tumor size. The degree of cellular differentiation (histological grade) was evaluated; 25 patients $(43.1 \%$ ) had grade 3 (undifferentiated) malignancies. The AFP level was $>500 \mathrm{ng} / \mathrm{mL}$ in 7 patients (12.1\%).

Fourteen patients (24.1\%) with type 2 diabetes mellitus (diagnostic criteria: fasting plasma glucose level $\geq 126 \mathrm{mg} / \mathrm{dL}$, hemoglobin A1c level $>6.5 \%$, or random glucose level $>200 \mathrm{ng} /$ $\mathrm{dL}$ with symptoms) were included in the evaluation. In addition, 25 patients (43.1\%) with obesity (body mass index [BMI] $>25 \mathrm{~kg} / \mathrm{m}^{2}$ ) were included in this study.

The treatment response was assessed by using followup computed tomography and magnetic resonance imaging. Intrahepatic failure was defined as recurrence in the liver, including both marginal recurrence and intrahepatic metastases; regional lymph nodal metastases were defined as regional lymph nodal recurrence (hilar, hepatoduodenal ligament, inferior phrenic, and caval lymph nodes). Distant metastasis was defined as metastasis to distant organs. Local control (LC), defined as time to recurrence in the liver, was selected as the primary endpoint of this study. The LC rate was calculated from the time of surgery. DFS was defined from the date of surgery to overall relapse (including both intrahepatic recurrence and extrahepatic recurrence), death, or last follow-up. OS was measured from the date of surgical resection to death or last follow-up. DFS was assessed as the secondary endpoint to estimate the treatment efficacy.

SPSS version 20.0 (IBM) was used for statistical evaluation. Fisher's exact test was used to evaluate the prognostic factors for treatment outcomes. For LC and survival analyses, the Kaplan-Meier method and the log-rank test were used for univariate analysis. The Cox proportional hazards model was used for multivariate analysis. Statistical significance was defined as $p<0.05$. In addition, $p<0.10$ was considered to indicate marginal significance.

\section{Results}

\section{Patterns of failure}

The median follow-up period was 23.3 months (range: 5.3-62.4 months). During the follow-up period, 20 patients (34.5\%) developed recurrences: 17 (29.3\%) developed intrahepatic (local) recurrence ( 5 cases of marginal failure and 12 cases of intrahepatic metastases), 1 (1.7\%) developed regional lymph node failure, and 8 (13.8\%) experienced distant metastases. The most frequent distant metastatic site was the lung, in 4 patients. Most patients $(13 / 17,76.5 \%)$ who experienced intrahepatic recurrence underwent transarterial chemoembolization as salvage treatment. During follow-up, 4 patients (6.9\%) died of recurrence. There were no deaths related to surgical complications.

Table II summarizes the clinical factors related to treatment outcome. Intrahepatic recurrence was associated with diabetes $(p=0.013)$ and AFP level $>500 \mathrm{ng} / \mathrm{mL}(p=0.019)$. Serosal invasion $(p=0.071)$ and $B C L C$ stage $B(p=0.082)$ also
TABLE II - Clinical factors related to treatment failure

\begin{tabular}{|c|c|c|c|c|}
\hline \multirow[t]{2}{*}{ Variables } & \multicolumn{2}{|c|}{$\begin{array}{l}\text { Intrahepatic } \\
\text { recurrence } \\
(n=17)\end{array}$} & \multicolumn{2}{|c|}{$\begin{array}{l}\text { Overall } \\
\text { relapse } \\
(n=20)\end{array}$} \\
\hline & No. & P value & No. & $P$ value \\
\hline T stage & & 0.172 & & 0.044 \\
\hline T1 & $11 / 44$ & & $12 / 44$ & \\
\hline $\mathrm{T} 2$ & $6 / 14$ & & $8 / 14$ & \\
\hline Tumor size (cm) & & 0.322 & & 0.218 \\
\hline$\leq 5$ & $13 / 48$ & & $15 / 48$ & \\
\hline$>5$ & $4 / 10$ & & $5 / 10$ & \\
\hline BCLC stage & & 0.082 & & 0.115 \\
\hline A & $15 / 56$ & & $18 / 56$ & \\
\hline B & $2 / 2$ & & $2 / 2$ & \\
\hline Milan criteria & & 0.27 & & 0.487 \\
\hline Inclusion & $12 / 47$ & & $15 / 47$ & \\
\hline Exclusion & $5 / 11$ & & $5 / 11$ & \\
\hline Liver cirrhosis & & 0.144 & & 0.158 \\
\hline Yes & $4 / 23$ & & $5 / 23$ & \\
\hline No & $13 / 35$ & & $15 / 35$ & \\
\hline Serosal invasion & & 0.071 & & 0.114 \\
\hline Yes & $1 / 4$ & & $3 / 4$ & \\
\hline No & $14 / 54$ & & $17 / 54$ & \\
\hline Microvascular invasion & & 0.216 & & 0.11 \\
\hline Yes & $4 / 8$ & & $5 / 8$ & \\
\hline No & $13 / 50$ & & $15 / 50$ & \\
\hline Resection margin involvement & & 0.66 & & 1 \\
\hline Yes & $1 / 6$ & & $2 / 6$ & \\
\hline No & $16 / 52$ & & $18 / 52$ & \\
\hline Histological grade & & 0.542 & & 0.414 \\
\hline G1-2 & $10 / 33$ & & $13 / 33$ & \\
\hline G3 & $7 / 25$ & & $7 / 25$ & \\
\hline Alpha fetoprotein (ng/mL) & & 0.019 & & 0.005 \\
\hline$\leq 500$ & $12 / 51$ & & $14 / 51$ & \\
\hline$>500$ & $5 / 7$ & & $6 / 7$ & \\
\hline Diabetes mellitus & & 0.013 & & 0.044 \\
\hline Yes & $8 / 14$ & & $8 / 14$ & \\
\hline No & $9 / 44$ & & $12 / 44$ & \\
\hline Obesity & & 0.317 & & 0.267 \\
\hline Yes & $6 / 25$ & & $7 / 25$ & \\
\hline No & $11 / 33$ & & $13 / 33$ & \\
\hline
\end{tabular}

$\mathrm{BCLC}=$ Barcelona Clinic Liver Cancer

showed a trend towards higher intrahepatic recurrence rates. Overall relapse was related to T stage $(p=0.044)$, AFP level $>500 \mathrm{ng} / \mathrm{mL}(p=0.005)$, and diabetes $(p=0.044)$. However, obesity was not associated with intrahepatic recurrence $(p=0.317)$ or overall relapse $(p=0.267)$. 


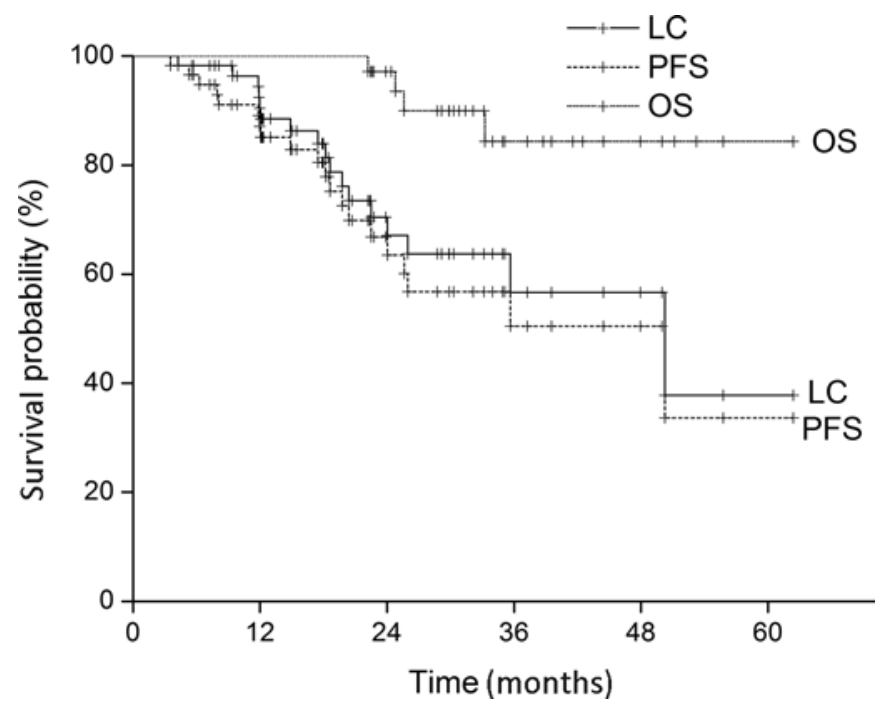

Fig. 1 - Local control (intrahepatic control) (LC), progression-free survival (PFS), and overall survival (OS).

Diabetes $(n=9)$ was also significantly correlated with intrahepatic recurrence in the subgroup analysis of patients with hepatitis B-related HCC ( $n=44, p=0.019$ by Fisher's exact test). Overall relapse tended to be affected by diabetes in patients with hepatitis B-related HCC $(p=0.068)$.

\section{Local control, disease-free survival, and overall survival}

Figure 1 shows the LC, DFS, and OS rates. The actuarial 1-year, 2-year, and 3-year LC rates were $90.4 \%, 67.1 \%$, and $56.7 \%$, respectively. The actuarial 1-year, 2-year, and 3-year DFS rates were $87.1 \%, 66.8 \%$ and $50.5 \%$, respectively. The 1-year, 2-year, and 3-year OS rates were estimated as $100 \%$, $97.1 \%$, and $84.3 \%$, respectively. Intrahepatic recurrence significantly reduced $O S(p=0.008)$.

\section{Prognostic factors}

Table III summarizes the analysis of prognostic factors for LC. BCLC staging (A vs. $B, p<0.001$ ), Milan criteria for transplantation $(p=0.041)$, serosal invasion $(p=0.032)$, and microvascular invasion $(p=0.043)$ were prognostic factors predictive of a poor outcome. Diabetes also significantly reduced the LC rate $(p=0.046 ;$ Fig. 2$)$. However, the prognostic significance of diabetes in LC did not extend to DFS $(p=0.160)$ or OS $(p=$ $0.264)$. Prognostic factors for DFS were AFP level $>500 \mathrm{ng} / \mathrm{mL}$ $(p=0.039)$, microvascular invasion $(p=0.027), B C L C$ staging $(p=0.040)$, and T stage (T1 vs. T2, $p=0.035)$. In the subgroup analysis for patients with hepatitis B-related HCC $(n=44)$, we found that diabetes $(n=9)$ also significantly reduced LC $(p=$ 0.028 ; Fig. 3). There were no independent prognostic factors for LC in this study (Tab. III). The relative risk of diabetes for local relapse was $1.60(95 \% \mathrm{Cl}=0.56-4.60)$. BCLC staging was an independent prognostic factor for DFS ( $p=0.040$, Tab. III).

Statistically significant changes of $L C$ as reflected by $T$ staging could not be observed in further evaluation. In the subgroup analysis for patients with stage T1 disease $(n=44)$, we could not find any significant prognostic effect of diabetes on $L C(p=0.134)$. There was also no significant effect of diabetes on LC $(p=0.265)$ in patients with stage T2 disease $(n=14)$.

\section{Subgroup analysis in patients with diabetes: anticancer effect of metformin}

Among the 14 patients who had diabetes, 5 patients used metformin for the treatment of diabetes. The use of metformin had no significant effect on intrahepatic recurrence $(p=0.580)$ or overall relapse $(p=0.357)$.

\section{Discussion}

The results of this study suggested that diabetes may increase the risk of intrahepatic relapse in early-stage postoperative $\mathrm{HCC}$ patients, and that diabetes may have a prognostic impact on $\mathrm{HCC}$ in areas endemic for hepatitis B. Active surveillance of $\mathrm{HCC}$ patients with diabetes and early detection of local relapse may improve LC by adequate timely management of these patients.

There are several possible mechanisms for the negative impact of diabetes on HCC progression. Diabetes-related vascular damage in the liver and release of vascular endothelial growth factor (22) may contribute to increased intrahepatic relapse. Increased insulin-like growth factor I or II levels (22), which are related to insulin insufficiency, may affect prognosis by stimulating cancer cell growth. Immune dysfunction caused by hyperglycemia can also increase the risk of HCC proliferation (23).

Diabetes is correlated with HCC incidence and recurrence. Davila et al (24) showed that the incidence of HCC was more than double $(H R=2.87)$ in patients with diabetes compared with nondiabetic individuals in a large cohort study conducted in the US. According to a study by Koh et al (25), Singapore Chinese with diabetes had an increased incidence of HCC $(H R=2.14)$ compared with nondiabetics. Additionally, Lai et al (26) reported that the incidence of HCC was twice as high in patients with diabetes $(H R=1.73)$ compared with nondiabetics in Taiwan. Our data are consistent with those presented in these studies. Diabetes was predictive of worse outcomes in patients with HCC after surgical resection in our study.

Good blood glucose control may reduce the rate of HCC progression. Not only diabetes mellitus but also impaired glucose tolerance, which is a prediabetic status of hyperglycemia, can affect the local recurrence of HCC. Lifestyle modifications (changing diet, exercise, and weight loss) for patients with insulin resistance (7) may be effective in reducing the risk of $\mathrm{HCC}$ progression. Further evaluation of glucose levels and the related serological markers could clarify the relationship between glucose metabolism and HCC.

Recently, metformin, an antidiabetic drug regulating cellular metabolism, has been widely used for cancer treatment (27). Although this study did not show any anticancer effect of metformin, most likely because of its small sample size, further comparative studies of cancer patients treated with or without metformin are warranted.

The role of obesity in $\mathrm{HCC}$ recurrence is still controversial (28). Park et al (29) argued that BMI $>25 \mathrm{~kg} / \mathrm{m}^{2}$ was not associated with increased mortality in Korean HCC patients, unlike 
TABLE III - Clinical factors affecting local control (intrahepatic control) and disease-free survival

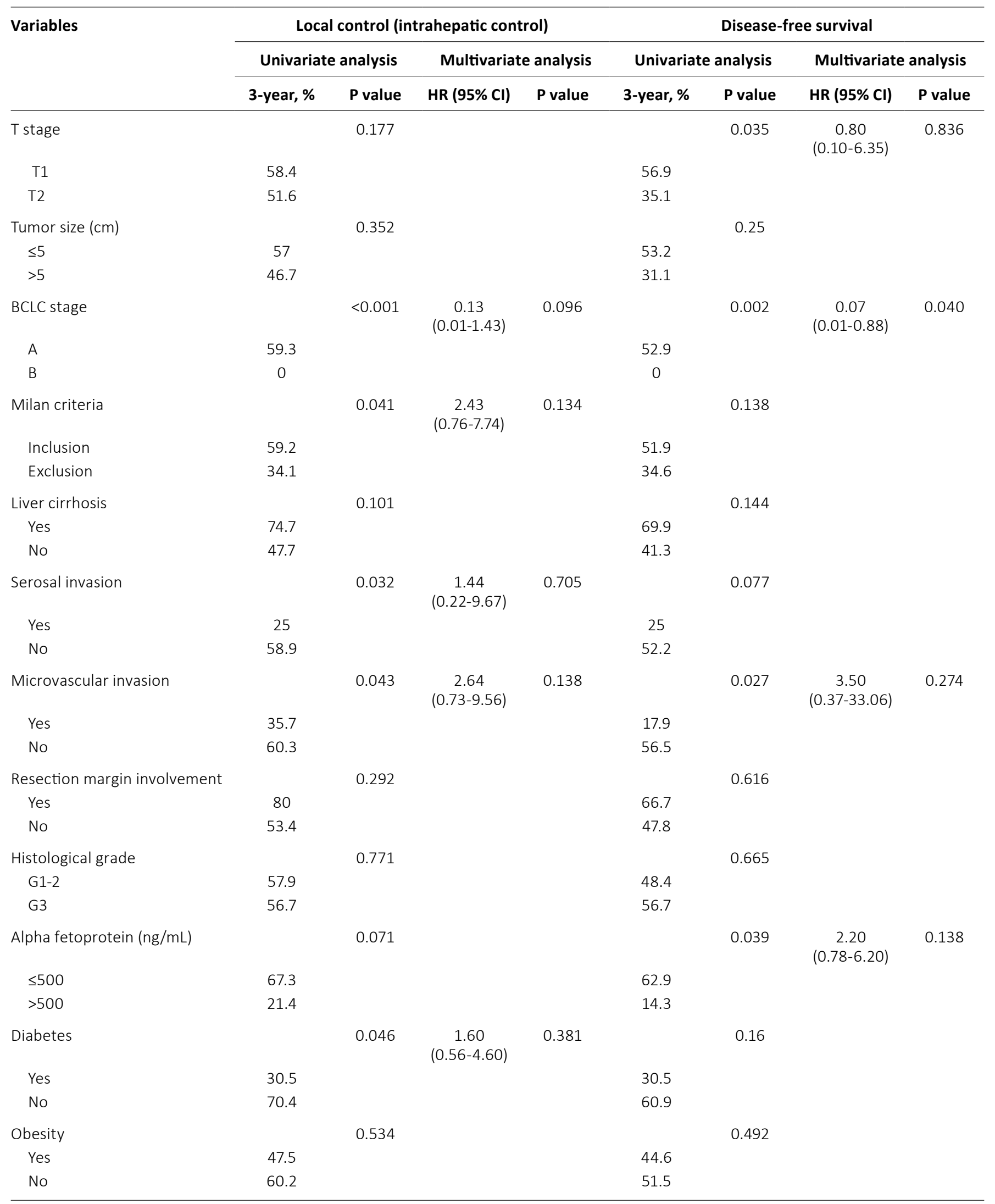

$\mathrm{BCLC}=$ Barcelona Clinic Liver Cancer $; \mathrm{Cl}=$ confidence interval; $\mathrm{HR}=$ hazard ratio. 


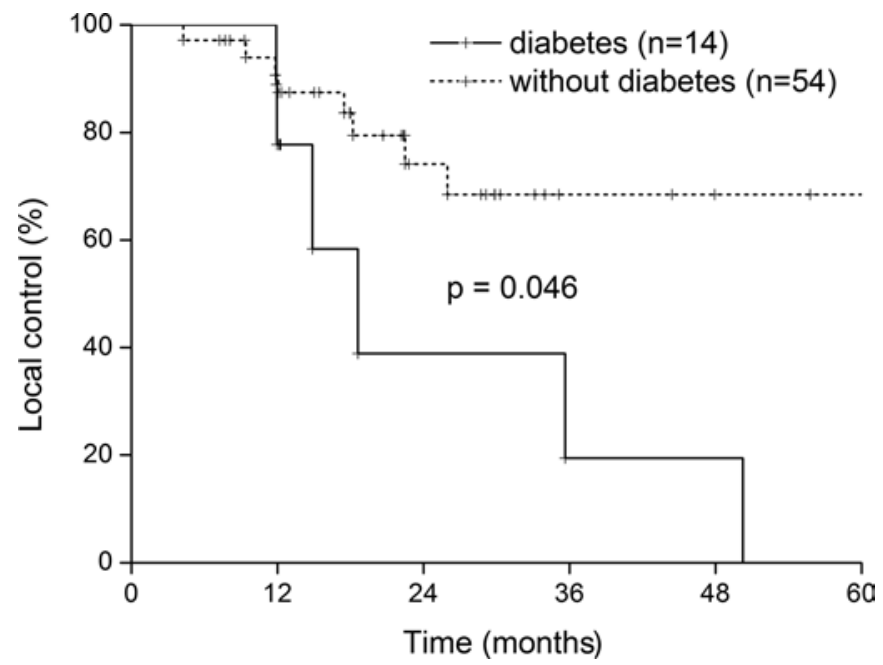

Fig. 2 - Impact of diabetes on local control (intrahepatic control) in postoperative hepatocellular carcinoma $(n=58, p=0.046)$.

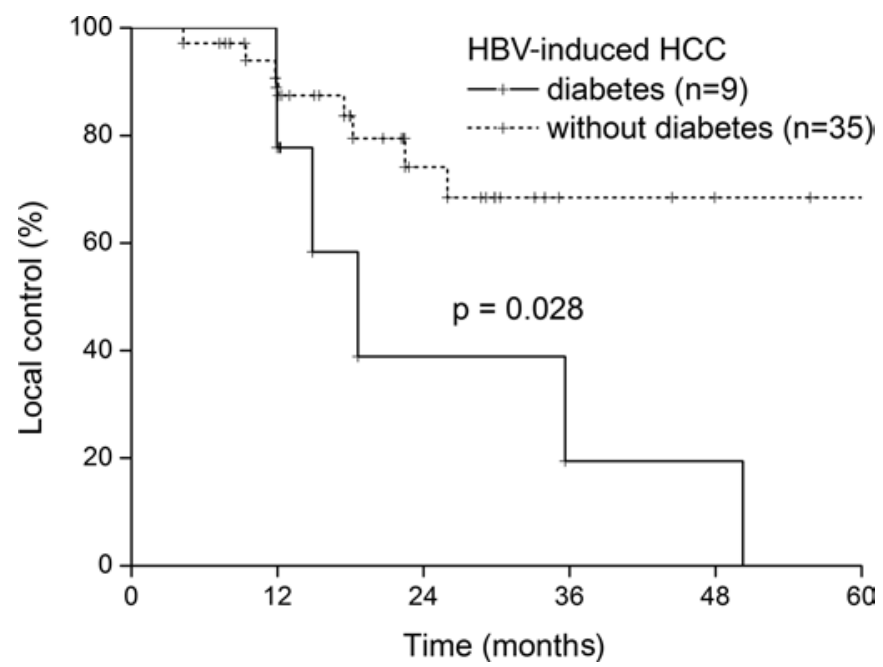

Fig. 3 - Subgroup analysis: local control (intrahepatic control) according to diabetes for hepatitis B-related hepatocellular carcinoma ( $n=44, p=0.028)$.

a previous study by Calle et al on cancer patients in the US (30), which showed that obesity (BMI $>40 \mathrm{~kg} / \mathrm{m}^{2}$ ) was associated with increased cancer death rates for HCC. Our study results also failed to identify obesity $\left(\mathrm{BMI}>25 \mathrm{~kg} / \mathrm{m}^{2}\right)$ as a risk factor for recurrence in resected HCC. However, obesity is one of the risk factors for type 2 diabetes. In addition, nutrition status is related to an increased risk of diabetes and HCC (31). Therefore, more studies should be performed on this topic in the near future.

This study has some limitations. First of all, it was retrospective, and because of the retrospective study design, selection bias may have influenced the outcome. Furthermore, the follow-up period was relatively short and the sample size relatively small. This study is on the hypothesis-generating level and the results should be interpreted with caution. A multicenter trial would be helpful, allowing the inclusion of a sufficient number of patients. Nevertheless, we did identify prognostic significance of diabetes in HCC.

In conclusion, diabetes mellitus is related to intrahepatic recurrence of HCC after curative resection. Diabetes is also related to intrahepatic recurrence of hepatitis B-related HCC. Therefore, HCC patients with diabetes mellitus should be monitored more carefully. Further large-scale, prospective studies are needed to provide more information about the association of diabetes with HCC.

\section{Abbreviations \\ AFP alpha-fetoprotein \\ BCLC Barcelona Clinic Liver Cancer \\ BMI body mass index \\ $\mathrm{Cl}$ confidence interval \\ DFS disease-free survival \\ HCC hepatocellular carcinoma \\ $\mathrm{HR}$ hazard ratio \\ LC local control \\ OS overall survival}

\section{Disclosures}

Financial support: None.

Conflict of interest: The authors have no conflict of interest to disclose.

\section{References}

1. Seyfried TN, Flores RE, Poff AM, D'Agostino DP. Cancer as a metabolic disease: implications for novel therapeutics. Carcinogenesis. 2014;35(3):515-527.

2. Seyfried TN, Shelton LM. Cancer as a metabolic disease. Nutr Metab (Lond). 2010;7(1):7.

3. Saxena NK, Sharma D, Ding $X$, et al. Concomitant activation of the JAK/STAT, PI3K/AKT, and ERK signaling is involved in leptinmediated promotion of invasion and migration of hepatocellular carcinoma cells. Cancer Res. 2007;67(6):2497-2507.

4. Fu SC, Huang YW, Wang TC, Hu JT, Chen DS, Yang SS. Increased risk of hepatocellular carcinoma in chronic hepatitis $B$ patients with new onset diabetes: a nationwide cohort study. Aliment Pharmacol Ther. 2015;41(11):1200-1209.

5. Siegel AB, Zhu AX. Metabolic syndrome and hepatocellular carcinoma: two growing epidemics with a potential link. Cancer. 2009;115(24):5651-5661.

6. Keum N, Greenwood DC, Lee DH, et al. Adult weight gain and adiposity-related cancers: a dose-response meta-analysis of prospective observational studies. J Natl Cancer Inst. 2015; 107(2):djv088.

7. Tsugane $S$, Inoue M. Insulin resistance and cancer: epidemiological evidence. Cancer Sci. 2010;101(5):1073-1079.

8. Wang WM, Xu Y, Yang XR, Wang YH, Sun HX, Fan J. Prognostic role of diabetes mellitus in hepatocellular carcinoma patients after curative treatments: a meta-analysis. Hepatobiliary Pancreat Dis Int. 2011;10(4):346-355.

9. Wang $\mathrm{YY}$, Huang $\mathrm{S}$, Zhong JH, et al. Impact of diabetes mellitus on the prognosis of patients with hepatocellular carcinoma after curative hepatectomy. PLoS ONE. 2014;9(12):e113858.

10. Komura T, Mizukoshi E, Kita Y, et al. Impact of diabetes on recurrence of hepatocellular carcinoma after surgical treatment in patients with viral hepatitis. Am J Gastroenterol. 2007; 102(9):1939-1946. 
11. Izumi R, Shimizu K, li T, et al. Prognostic factors of hepatocellular carcinoma in patients undergoing hepatic resection. Gastroenterology. 1994;106(3):720-727.

12. Wu JC, Huang $\mathrm{YH}, \mathrm{Chau} \mathrm{GY}$, et al. Risk factors for early and late recurrence in hepatitis B-related hepatocellular carcinoma. J Hepatol. 2009;51(5):890-897.

13. Lee JH, Kim TI, Jeon SM, Hong SP, Cheon JH, Kim WH. The effects of metformin on the survival of colorectal cancer patients with diabetes mellitus. Int J Cancer. 2012;131(3):752-759.

14. Cufí S, Corominas-Faja B, Lopez-Bonet E, et al. Dietary restriction-resistant human tumors harboring the PIK3CAactivating mutation $\mathrm{H} 1047 \mathrm{R}$ are sensitive to metformin. Oncotarget. 2013;4(9):1484-1495.

15. Shackelford DB, Shaw RJ. The LKB1-AMPK pathway: metabolism and growth control in tumour suppression. Nat Rev Cancer. 2009;9(8):563-575.

16. Vallianou NG, Evangelopoulos A, Kazazis C. Metformin and cancer. Rev Diabet Stud. 2013;10(4):228-235.

17. Parkin DM, Bray F, Ferlay J, Pisani P. Global cancer statistics, 2002. CA Cancer J Clin. 2005;55(2):74-108.

18. de Lope CR, Tremosini S, Forner A, Reig M, Bruix J. Management of HCC. J Hepatol. 2012;56(Suppl 1):S75-S87.

19. Jung KW, Won YJ, Oh CM, et al. Prediction of cancer incidence and mortality in Korea, 2016. Cancer Res Treat. 2016;48(2): 451-457.

20. Llovet JM, Brú C, Bruix J. Prognosis of hepatocellular carcinoma: the BCLC staging classification. Semin Liver Dis. 1999;19(3): 329-338.

21. Elshamy M, Aucejo F, Menon KV, Eghtesad B. Hepatocellular carcinoma beyond Milan criteria: management and transplant selection criteria. World J Hepatol. 2016;8(21):874-880.

22. Kaseb AO, Morris JS, Hassan MM, et al. Clinical and prognostic implications of plasma insulin-like growth factor-1 and vascular endothelial growth factor in patients with hepatocellular carcinoma. J Clin Oncol. 2011;29(29):3892-3899.

23. Pardee AD, Butterfield LH. Immunotherapy of hepatocellular carcinoma: unique challenges and clinical opportunities. Oncolmmunology. 2012;1(1):48-55.

24. Davila JA, Morgan RO, Shaib Y, McGlynn KA, El-Serag HB. Diabetes increases the risk of hepatocellular carcinoma in the United States: a population based case control study. Gut. 2005; 54(4):533-539.

25. Koh WP, Wang R, Jin A, Yu MC, Yuan JM. Diabetes mellitus and risk of hepatocellular carcinoma: findings from the Singapore Chinese Health Study. Br J Cancer. 2013;108(5): 1182-1188.

26. Lai SW, Chen PC, Liao KF, Muo CH, Lin CC, Sung FC. Risk of hepatocellular carcinoma in diabetic patients and risk reduction associated with anti-diabetic therapy: a population-based cohort study. Am J Gastroenterol. 2012;107(1):46-52.

27. Kourelis TV, Siegel RD. Metformin and cancer: new applications for an old drug. Med Oncol. 2012;29(2):1314-1327.

28. Hamaguchi Y, Kaido T, Okumura S, et al. Preoperative intramuscular adipose tissue content is a novel prognostic predictor after hepatectomy for hepatocellular carcinoma. J Hepatobiliary Pancreat Sci. 2015;22(6):475-485.

29. Park SM, Lim MK, Shin SA, Yun YH. Impact of prediagnosis smoking, alcohol, obesity, and insulin resistance on survival in male cancer patients: National Health Insurance Corporation Study. J Clin Oncol. 2006;24(31):5017-5024.

30. Calle EE, Rodriguez C, Walker-Thurmond K, Thun MJ. Overweight, obesity, and mortality from cancer in a prospectively studied cohort of U.S. adults. N Engl J Med. 2003; 348(17):1625-1638.

31. Smith RJ. Nutrition and metabolism in hepatocellular carcinoma. Hepatobiliary Surg Nutr. 2013;2(2):89-96. 